\title{
O RURAL QUILOMBOLA DO RIO BAIXO ITACURUÇÁ-PA: ASPECTOS DA CULTURA, EDUCAÇÃO E RURALIDADE*
}

\author{
Eliana Campos Pojo**
}

\begin{abstract}
Resumo: $\mathrm{O}$ artigo propõe caracterizar o 'rural' de uma comunidade ribeirinha e quilombola localizada no rio baixo Itacuruçá-Abaetetuba/PA. O estudo desenvolveuse pautado nas discussões, nas leituras e nas incursões ao 'campo' por meio de pesquisa dentro da abordagem etnográfica, enfatizando o 'ser quilombola' nessa localidade, tomando como foco a ruralidade presente na comunidade, as condições socioculturais e a institucionalidade da Escola quilombola na interface com os estudos teóricos sobre o 'mundo rural' no Brasil. Mundo esse cercado por águas, florestas, marés, criação de animais domésticos, plantas, barcos, vidas indo e vindo na particular paisagem ribeirinha e quilombola.
\end{abstract}

Palavras-chave: Rio baixo Itacuruçá. Comunidade ribeirinha e quilombola. Diversidade cultural. Ruralidade.

The rural quilombola in the Low river Itacuruçá-PA: aspects of culture, education and rurality

Abstract: The paper aims to characterize the 'rural' of a riverside and quilombola community located in Itacuruçá-Abaetetuba/PA river in Brazil. The study was guided by discussions, readings and incursions in the 'field' through research using an ethnographic approach, emphasizing the 'quilombola being' into this locality, taking as the focus the rurality and sociocultural conditions

* Agradeço aos comentários e sugestões realizadas pelo Prof. Dr. Carlos Rodrigues Brandão (UNICAMP), durante o processo de elaboração deste artigo.

** Universidade Federal do Pará, Abaetetuba-PA, Brasil (lilicapojo@gmail. com). Recebido em: 30/10/2014 - Aceito em: 29/06/2015. 
$|144|$

O rural quilombola...

of this community and the institutionality of the quilombola School in the interface with the theoretical studies of the 'rural world' in Brazil. It is a world surrounded by water, forests, tides, animal husbandry, plants, boats, lives coming and going in the unique landscape of this riverside and quilombola place.

Keywords: Itacuruçá river. Riverside and quilombola community. Cultural diversity. Rurality.

El rural quilombola del río Bajo Itacuruçá-PA: aspectos de la cultura, educación y ruralidad

Resumen: El artículo se propone a caracterizar lo "rural" de una comunidad ribereña y quilombola ubicada en el río bajo Itacuruçá, in Abaetetuba/Pará. El estudio se desarrolló en base a debates, lecturas y en las incursiones al 'campo' mediante la investigación dentro del enfoque etnográfico, enfatizando el 'ser quilombola' en esta localidad, tomando como foco la ruralidad presente en la comunidad, las condiciones socioculturales y la institucionalidad de la Escuela quilombola en el interfaz con los estudios teóricos sobre el 'mundo rural' en Brasil. Mundo éste rodeado por las aguas, forestas, mareas, creación de animales domésticos, plantas, barcos, vidas yendo y viniendo en el particular paisaje ribereño y quilombola.

Palabras clave: Río bajo Itacuruçá. Comunidad ribereña y quilombola. Diversidad cultural. Ruralidad.

\section{Introdução}

O presente artigo pretende caracterizar o 'rural' da comunidade ribeirinha e quilombola Nossa Senhora do Perpétuo Socorro, localizada no rio baixo Itacuruçá-Abaetetuba/PA, refletindo a diversidade cultural existente ali, manifestada por meio das tradições, dos saberes e dos fazeres populares, assim como, de sistemas de crenças e valores que conformam e atribuem sentido aos seus modos de viver e de significar a existência.

Para tanto, recorremos a incursões ao 'campo', propiciadas pelo projeto de pesquisa "Travessias, identidades e saberes das águas - cartografias de saberes de populações ribeirinhas no Município de Abaetetuba-PA" (UFPA, 2013). Enquanto uma experiência educativa integrada, a nossa vivência neste projeto abarcou um caminho metodológico que abrangeu múltiplos entrelaçamentos envolvidos nas situações e nos processos sociais 
da comunidade. Neste percurso a "participação observante" foi primordial e, para isso, interagimos com representantes do movimento social de ribeirinhos e quilombolas, com lideranças da comunidade e da escola, resultando um conjunto interativo, composto de diversos materiais, tais como: mapas geográficos; depoimentos e entrevistas produzidos com lideranças, moradores e estudantes; registros fotográficos dos percursos realizados no lugar; diários de campo; documentos oficiais de movimentos sociais e de escolas.

O foco deste estudo é aprofundar o debate acerca do 'mundo rural', a partir de estudos teóricos sobre o tema, na interface com a ruralidade presente nessa comunidade e, dessa forma, dar ênfase ao reconhecimento de sua cultura (culturas), tomando, para tanto, vetores como: os modos de vida, as práticas culturais locais, os saberes dos sujeitos ribeirinhos e quilombolas, enfim, as práticas sociais que produzem uma dada identidade amazônica e regional.

No percurso da pesquisa, evidenciamos traços culturais que substanciam de forma própria uma observação acurada dos moradores sobre as mudanças do rio, o domínio da localização geográfica das ilhas e das florestas e da natureza em geral; estabelecem com as águas uma relação de respeito vinculando a elas as situações de assombrações, de símbolos, de vida, de sentidos próprios de quem vive ali, ou seja, representações simbólicas e valorativas que lhes dão a identidade de povo e a de comunidade. Dito de outra forma, as manifestações culturais presentes na comunidade estão presentes nos modos de vida representados pelo trabalho na terra, na floresta e no rio; nas brincadeiras do form $\hat{o}^{1}$; na travessia cotidiana até a $u r b i s^{2}$ e, especialmente, nos seus saberes

\footnotetext{
${ }^{1}$ Essa brincadeira consiste na demarcação do espaço onde cada integrante do grupo impede a invasão do seu espaço (quadrado) e o movimento do corpo expressa gingados parecidos com os da capoeira.

2 Trata-se de uma definição de cidade referindo-se ao contexto urbano. Sendo espaço social, a urbis é onde se concentra a formalidade das instituições e, também, do estado, representado pelo poder local, entidades sociais, os serviços públicos etc.
} 
$|146|$

O rural quilombola...

da relação com a natureza. Nesse sentido, muitos moradores afirmam que "o território quilombola é privilegiado porque todas as comunidades são nascentes de rios". Com isso, evidencia-se uma estreita relação de pertencimento entre a comunidade e o rio.

Nessa comunidade existe um peculiar modo de viver, que é identificado seja através das formas próprias de trabalho, seja por meio da ação social (lazer, travessia, escola, etc.). Ele é pautado pelo relógio natural impresso e expressado pelos rios; pelos saberes derivados da convivência íntima com ele, assim como pelas formas culturais produzidas a partir das práticas sociais como o cultivo e o manejo do açaí, da produção de diversos tipos de farinha, do uso versátil do miriti ${ }^{3}$, da feitura das roças, das atividades de pesca, da antiga forma de pescar camarão com matapi ${ }^{4}$. E também pela rica produção artesanal com uso de talas na fabricação de paneiros, de rasas, de tipitis ${ }^{5}$ e de sementes na fabricação de adereços, assim como pelo domínio de regras de fabricação e de uso de utensílios como o matapi, pelo uso da peconha ${ }^{6}$ para subir nos açaizeiros e pelo tecer a rede de pescar com o emprego de práticas patrimoniais de produção.

A perspectiva adotada é a do atravessamento de um 'mundo rural' peculiar, situando o contexto social concreto da comunidade, buscando expressar sentidos e significados do cotidiano nas diversas relações sociais. Sentidos e significados que nem sempre encontram ressonância, por exemplo, na escola rural existente naquele lugar. Tal como costuma acontecer em outros contextos

\footnotetext{
${ }^{3} \mathrm{O}$ miriti é a fibra do buritizeiro (palmeira que dá fruto chamado buriti). Tanto a fibra quanto o fruto podem ser utilizados de várias formas artesanais ou não. O município de Abaetetuba é também conhecido pelo trabalho de artesãos na produção de brinquedos de miriti.

${ }^{4}$ Utensílio de pegar o camarão feito na própria comunidade.

${ }^{5}$ São objetos feitos com tala e são utilizados nas atividades de coleta do açaí e na produção da farinha.

${ }^{6}$ Utensílio feito artesanalmente da folha do açaizeiro (ou de corda) pelos apanhadores de açaí e é utilizado para subir na palmeira e coletar seu fruto.
} 
rurais no Brasil, de certa forma a escola local assume na sua prática educativa uma hegemonia e forânea diante da diversidade cultural local. Assim, no presente trabalho, ancoramo-nos nos estudos teóricos sobre o campesinato brasileiro, sobre o mundo rural e sobre a sua diversidade, ao lado de questões de identidades, também através da observância do 'campo' na perspectiva de compreender a diversidade cultural e o 'mundo rural' existente, assim como as suas relações com aspectos educacionais proveniente da educação oficial.

\section{O viver ribeirinho e quilombola do rio baixo Itacuruçá}

De acordo com a versão dos moradores da comunidade, há uma distinção clara entre 'ribeirinho e quilombola': "O quilombola é aquele que mora em terra firme e o ribeirinho é aquele que mora às margens do rio, porque tem o ribeirinho e tem o quilombola; nós somos quilombola". Para ratificar a distinção, alguns moradores nos solicitaram que fossem reconhecidos na pesquisa como quilombolas, por considerarem essa particularidade como importante marca de diferenciação entre os dois povos. Admitindo também a compreensão do termo "populações tradicionais", adotaremos nesse escrito os dois termos. (Morador do rio baixo Itacuruçá, 2013)

Se há uma distinção sociocultural entre ribeirinhos e quilombolas, há também uma outra distinção que é territorial, e de caráter geopolítico. As terras de uma população e da outra são separadas pelo rio Baixo Itacuruçá. Tal separação funciona como a demarcação territorial dos povos da comunidade Nossa Senhora do Perpétuo Socorro. Assim, de um lado do rio ficam os moradores ribeirinhos nas terras pertencentes à Marinha, e do outro ficam os quilombolas, moradores no território demarcado como remanescente de quilombo desde 2002, período em que essas terras foram credenciadas pelo Instituto de Terras do Pará - ITERPA e pelo Instituto Nacional de Reforma Agrária - INCRA. Dessa diferença deriva a inserção deles em algumas políticas sociais. As práticas sociais do cotidiano encontram-se mescladas 
| 148 |

O rural quilombola...

e são controversas, sendo a beira-rio e a floresta espaços referenciais dos grupos que, num movimento social, cultural e de saberes que lhes é peculiar, interagem com todos estes elementos similares, tanto aos ribeirinhos quanto aos quilombolas, que os percebem e os vivenciam sem que haja uma distinção do território em suas práticas cotidianas atuais.

O rio baixo Itacuruçá situa a comunidade Nossa Senhora do Perpétuo Socorro na região das ilhas de Abaetetuba, estando a mesma, portanto, localizada entre os rios Arapapu e Piquiarana. Para percorrê-lo da urbis à comunidade, leva-se em torno de uma hora e consta em dados oficiais que a referida comunidade possui aproximadamente 126 famílias.

O município de Abaetetuba é constituído por aproximadamente setenta e duas (72) ilhas entrelaçadas por rios, furos ${ }^{7}$ e igarapés interligados uns aos outros. $\mathrm{O}$ 'rural' é assentado numa geografia de ilhas, de estradas e de ramais e dentro dele estão onze comunidades quilombolas existentes e diversas outras que são identificadas como ribeirinhas (CPT e Moriva, 2009:42); (ROCHA, 2012).

Os ribeirinhos e quilombolas localizam-se geograficamente, construindo uma forma própria de lidar com o tempo-espaço entre as águas, seus trabalhos, suas maneiras patrimoniais de lidar com o rio como meio de transporte, como provedor de alimentos e até mesmo como indicador de identidades, de que é exemplo a afirmação: "a gente foi criado n'água", reiterando que esse tempo-espaço é mutante, cíclico e natural. Eles sabem lidar com o rio seja pela disposição em navegar dia a dia entre as águas, seja por possuírem um conhecimento peculiar sobre a 'essência viva' das marés vazantes, cheias, de lance, de quebra. Seja, ainda, por saberem, com precisão, o tempo das águas para navegar nas embarcações, as fases da lua e sua relação com o rio,

\footnotetext{
${ }^{7}$ Furo é um termo amazônico e caracteriza-se por ser um canal estreito de um rio. São córregos que unem rios maiores entre si, normalmente em matas de várzeas, servindo de atalho às distâncias entre as comunidades de ilhas e a urbis.
} 
confirmando os "saberes das águas" construídos pelos sujeitos que interagem cotidianamente com eles. Adotando o enfoque da obra de Wanderley (2011:120), podemos dizer que se trata de ruralidades construídas, termo que se refere "às particularidades do espaço rural, às relações, às representações e aos sentimentos de pertencimento, referidos ao meio rural e aos modernos processos de integração campo-cidade".

Durante as incursões ao 'campo' buscamos apreender as diferentes culturas das populações locais, nas peculiaridades diárias manifestadas pela comunidade, realizando "andanças" e estabelecendo relações sociais com as pessoas e o lugar, visualizando como se desenvolve a vida ali. Pois entendemos que as práticas sociais do cotidiano são reveladoras dos conteúdos da vida local, na medida em que simbolizam e traduzem aspectos culturais, e, associadas ao que esperamos que a escola aporte, contribuindo para a formação de uma "consciência cidadã", pois, conforme Brandão (2002:41) "ser o sujeito da história e ser o agente criador da cultura não são adjetivos qualificadores do homem. São o seu substantivo. Mas não são igualmente sua essência e sim um momento do seu próprio processo de humanização".

Neste processo do existir do homem rural, a ruralidade do rio baixo itacuruçá constitui-se de experiências de trabalho na agricultura, com suas formas viver, produzir e resistir, através de suas diversas formas de relações sociais, de que o processo de demarcação de suas terras é apenas uma dimensão. O que supõe entender que esse 'rural' é complexo, tendo especificidades como um espaço de vida. Em outros termos, "o rural tem uma natureza qualitativamente distinta - relações de vizinhança e parentesco, solidariedade, mutirões, atividades coletivas, práticas artesanais, dinamizando símbolos culturais, que dificilmente têm lugar nas grandes cidades", mas há vínculos que correlacionam o mundo rural ao conjunto da sociedade brasileira em muitos aspectos como a cultura, a educação e a economia, mesmo sendo esta última a mais forte devido ao modelo de desenvolvimento adotado (KAGEYAMA, 2008:16, grifos nossos). 
| 150 |

O rural quilombola...

Nós compreendemos este 'rural' como uma processualidade derivada de múltiplas aprendizagens. Razão pela qual buscamos observar a natureza-cotidiano, captando as entrelinhas do não dito, ouvindo o inaudível, consolidando a interação do grupo de pesquisa com os sujeitos da comunidade em estudo, em síntese, o adentrar cuidadosamente numa realidade sintonizada com o "deixar-se molhar pela cultura" será a abordagem dada à dimensão ruralidade na comunidade do rio baixo Itacuruçá, aspecto a ser tratado no tópico seguinte (FREIRE, 1995).

\section{A ruralidade ribeirinha e quilombola num pedaço da Amazônia paraense}

A Amazônia é interpretada a partir de diferentes olhares e compreensões de acordo com o tempo histórico, com o enfoque legal e teórico, com o interesse político, econômico e social. Porém, todos esses olhares focalizam usualmente a importância da Amazônia para a vida humana e para a vida de outras espécies. Em tais focos, estão presentes, além da biodiversidade tão propagada, diferentes territórios com pessoas que vivem suas vidas entrelaçadas pelo ambiente natural, a partir do que se reproduzem e transformam as suas culturas locais.

A cotidianidade de comunidades tradicionais como as ribeirinhas e as quilombolas já vem sendo retratada por diversos estudiosos como Diegues (1998; 2000), Gusmão (2013), Brandão (1995). Na comunidade Nossa Senhora do Perpétuo Socorro, especificamente, visualizamos a cotidianidade do povo no movimentar-se pelo rio através de um modo "rural" vivido pelos seus habitantes entre atividades agrícolas, artesanais, de pesca e de comercialização de produtos. São pessoas que nascem, que vivem e que se criam à beira de rios e nas florestas, cunhando um determinado desenvolvimento rural.

Nossa intenção é dar visibilidade para as nuances do 'rural e de suas ruralidades'. Para isso, utilizamos como referência principal, mas não única, os estudos contidos na obra intitulada "Um saber necessário: os estudos rurais no Brasil", na perspectiva 
de construir um diálogo sobre o 'rural' ribeirinho e quilombola do rio baixo Itacuruçá-PA (WANDERLEY, 2011).

A obra de Maria de Nazareth Baudel Wanderley tem sua relevância por "fazer um balanço da produção científica" sobre a questão rural brasileira, situando o que ela define como sendo "olhares plurais e complementares sobre processos sociais" de construção científica e política do mundo rural, embora em constante mutação. Todavia, nesse fazer, a autora não tem a pretensão de dar conta da totalidade da história rural, mas, sim, sem procurar resumi-la, elucidando alguns marcos conceituais fundamentais, principalmente aqueles que se referem a uma compreensão mais perfilada do complexo, do diverso e do importante 'mundo rural' como parte substancial no desenvolvimento social da sociedade como um todo (WANDERLEY, 2011:20-21).

O 'rural', enfatizado na obra, é um elemento de análise para se pensar o desenvolvimento do país, incluindo neste desenvolvimento outros aspectos além do econômico, tão propagado. Também são ressoantes as múltiplas conceituações, categorizações e relações do 'rural' numa imbricação com a vida das pessoas e com o mundo urbano e globalizado. Diante da efervescência de mudança, alteram-se afirmações e conceituações sobre o rural pelos estudiosos, em especial nos estudos de Brandão (1995) e de Almeida (1995 e 2007), que convidam a outras interpretações para o paradigma da agricultura e para o sujeito rural e suas temporalidades.

Dos estudiosos e estudos em contextos concretos, alguns extratos nos ajudam a pensar sobre o 'rural ribeirinho e quilombola' tal como proposto neste escrito. Assim, passamos a situá-los a partir dos contornos feitos através da pesquisa que vimos realizando, procurando desvendar um "social" com jeitos, com cheiros, com sabores, com saberes e com fazeres rurais próprios.

Assim sendo, um dos aspectos marcantes na comunidade Nossa Senhora do Perpétuo Socorro, que específica esse 'rural', são as formas de trabalho. A agricultura ainda é forte e resiste às 
$|152|$

O rural quilombola...

adversidades sociais e econômicas. É presente o cultivo do açai ${ }^{8}$ por conta de estar a comunidade na beira do rio (área de várzea) e a terra ser mais fértil para esse tipo de plantio. Ao lado do açaí, em terra firme persiste o cultivo da roça com a plantação de maniva", milho, quiabo, jerimum, maxixe, arroz e "outras coisas de legume" como produtos cultivados para a venda e para o consumo das famílias.

Além das alternativas já citadas, existem outras formas de trabalho na comunidade, tais como o as atividades realizadas em olarias construídas à margem dos rios pela facilidade do embarque do barro, da lenha e do escoamento da produção de tijolo e de telha. É forte também a pesca de peixe e de camarão. E não se deve esquecer os que atuam como rabeteiros, transportando pessoas e materiais até a urbis e, também, os que constroem as rabetas ${ }^{10}$. Essas modalidades de trabalho acontecem de forma múltipla e simultânea, ou seja, muitas vezes a mesma família trabalha na olaria, tem cultivo na roça e atua com a pesca. Assim, tais atividades constituem em seu conjunto a parte essencial do sustento das famílias. As múltiplas e simultâneas formas de trabalho são expressas na afirmação de uma das moradoras, que diz: "Porque é assim. Tudo depende da época e do período". (Moradora do rio baixo Itacuruçá, 2013)

\footnotetext{
${ }^{8}$ Para o cultivo do açaí, há os peconheiros que realizam atividade diária de apanhar o produto. Muitos utilizam, nesse fazer, o sistema de meia, ou seja, o proprietário divide o açaí apanhado em partes iguais com o apanhador. $\mathrm{Na}$ maioria das vezes, as crianças e os adolescentes aprendem a apanhar o açaí, observando o pai e os irmãos mais velhos, o que, muitas vezes, é uma forma de brincar também; em outras situações, isso se torna uma atividade laboral de ajuda no sustento da família.

${ }^{9}$ Maniva é a folha da mandioca que é utilizada, após seu cozimento, para o prato tipicamente paraense, a maniçoba.

${ }^{10}$ Rabetas são pequenas embarcações motorizadas que podem ser cobertas (com toldo) ou descobertas, normalmente de pequeno porte. Tais embarcações fazem o percurso das comunidades das ilhas até a urbis do município levando cargas e passageiros. E, rabeteiros são moradores que trabalham como condutores dessas rabetas.
} 
O trabalho na comunidade ribeirinha e quilombola envolve de maneira diferenciada os homens, as mulheres, as crianças, os jovens e também os idosos. Nas andanças na comunidade presenciamos mulheres pilotando rabetas, pescando camarão, carregando lenha para fazer carvão. E também envolvidas com as tarefas domésticas, com o plantio da roça, com a produção da farinha, e ainda debulhando o açaí.

Com relação aos homens, além das atividades que citamos desenvolvidas pelas mulheres, eles se envolvem também com a venda de produtos na cidade, apanham o açaí, cortam e fazem o carreio ${ }^{11}$ da lenha ou da madeira, produzem o carvão, pescam e atuam nas olarias. Observamos que a agricultura nesse contexto possui grande capacidade produtiva e sua produção serve para subsidiar outros locais fora da comunidade.

Ainda sobre a agricultura, o açaí continua sendo o principal produto da comunidade e da cidade, tanto que muitos moradores utilizam a seguinte fala: "Trabalhamos para ter o que comer o ano todo". Nessa atividade, os homens sobem nos açaizeiros e apanham os cachos, as mulheres os debulham e as crianças os ajudam nesta tarefa. Assim, estamos diante de uma modalidade coletiva e partilhada de trabalho que faz parte do cotidiano familiar. Na safra do açaí, é também comum o "trabalho de empreita", o que corresponde à negociação entre produtores e apanhadores, ambos moradores da própria comunidade.

$\mathrm{O}$ trabalho nas múltiplas atividades mencionadas realiza-se em uma dimensão profundamente relacional, ou seja, existe uma "natureza das relações de produção" que envolve diferentes conversas sobre as questões da vida, sobre o ensino dos modos de fazer entre pais e através das trocas geracionais entre adultos, jovens e crianças. E também na contação de 'causos' durante as caminhadas até os espaços de trabalho.

Esta forma de trabalhar, típica das comunidades camponesas, em que os sujeitos imprimem seus próprios ritmos, seus tempos,

${ }^{11}$ Forma de carregar madeira e carvão utilizando um animal, normalmente são bois.

Idéias - Rev. Inst. Filos. Ciênc. Hum. UNICAMP, v.6, n.1, p. 143-164, jan./jun. 2015 
$|154|$

O rural quilombola...

suas lógicas e também materializam processos próprios, não tem como principal motivação o mero valor lucrativo, mas o seu foco está na "reprodução da família para si", o seu bem estar dentro dos moldes de um viver dignamente (ALMEIDA, 1986:66-67).

Atualmente, presenciamos o forte avanço do monocultivo do dendê na região do Baixo Tocantins ${ }^{12}$, o que ocasiona vários problemas e de diversas ordens, como a expropriação fundiária (transferência de terras públicas ou particulares) e a compra de terras por empresas ${ }^{13}$ com documentação de valor jurídico duvidoso. Eis o motivo pelo qual os movimentos sociais, associados ao poder judiciário (sindicatos de trabalhadores rurais, organizações da região com o apoio da FASE Amazônia ${ }^{14}$ e do Ministério Público Estadual) estão se mobilizando para discutir a questão.

Atrelado ao plantio do dendê temos o problema ambiental. Tal problemática se deve, dentre outros fatores, ao uso crescente de agrotóxicos nessa cultura, sendo o seu impacto visível nos vários rios, furos e igarapés, afetando os peixes, a água, o ecossistema. E esse avassalador potencial mercadológico tende a submeter imensa parte da agricultura da região. Todavia, atualmente ainda não temos "estudos sobre os impactos desses agrotóxicos na Amazônia, ninguém sabe quanto dendê foi plantado e quanto veneno foi jogado nas terras e nos igarapés" (FASE Amazônia, 2014:4).

Outra questão de impacto é o crescimento do negócio empresarial que cria uma relação de dependência dos agricultores, isto é, "os trabalhadores que assinam os contratos com as empresas praticamente se tornam empregados delas, não de forma jurídica, mas agregando-se de maneira a não ter quase nenhum

\footnotetext{
12 São municípios pertencentes à região do Baixo Tocantins: Abaetetuba, Barcarena, Acará, Moju e Igarapé-Miri.

${ }^{13}$ Nessa região do Baixo Tocantins estão presentes as empresas Biofarma, Agropalma e a Biovale como o pretenso discurso de que chegam trazendo o 'progresso'.

14 Trata-se de uma entidade que realiza atividades junto a populações rurais.
} 
aproveitamento de sua própria terra" (FASE Amazônia, 2014:5). Há casos de agricultores, principalmente os jovens, que 'vendem' sua força de trabalho, deslocando-se para as 'fazendas' onde estão situadas as plantações do dendê. Tais procedimentos explicitam a perda da autonomia e do compartilhamento familiar, quando esses sujeitos deixam de ser os atores sociais e históricos de suas produções e de seus valores sociais, e passam a ser tutelados por essas empresas. Em muitos casos tal fato constitui-se como uma demonstração cruel de que a exploração dos trabalhadores é uma ferramenta efetiva para a acumulação capitalista. Em outros termos, estamos a presenciar nesse nosso cenário "o controle da fronteira pelo capital" (WANDERLEY, 2011:38).

Aos poucos vai se perdendo, através do processo de múltiplas expropriações e subordinações das populações locais, a preservação social de uma agricultura com base na necessidade vital e no saber dos agricultores. E, mais ainda, no seu afeto pela terra, pelo livre plantio diversificado, e ainda em um modo de produzir humanizado que significa, para eles, o viver dignamente. Muitos são os traços dessa ruralidade ribeirinha $\mathrm{e}$ quilombola que estão postos, e uma primeira interpretação que se faz dela é a de "compreensão do mundo rural e suas relações com as cidades, bem como nas relações da vida local com os processos de globalização". Não obstante, a produção da vida rural e um "ethos" rural também devem ser compreendidos não meramente do ponto de vista econômico, mas também desde o ponto de vista de toda uma luta em nome do construir outro modelo de desenvolvimento. Um "desenvolvimento rural sustentável como projeto de sociedade" (WANDERLEY, 2011:106).

Em nossa tentativa de expressá-lo, procuramos apreender o rural ribeirinho e quilombola como um complexo social de vida cotidiana com as suas cores, seus saberes e seus sabores, suas interações com a natureza e entre diferentes categorias de pessoas e instituições da comunidade e de fora dela. Com seus dilemas, conflitos e contradições também. No cotidiano, de fato uma imbricação campo-cidade é parte hoje em dia cada vez mais essencial na vida dos ribeirinhos e quilombolas, seja pela 
necessidade de transações de compra e venda de produtos na urbis, seja pela relação de saberes e, de maneira especial, na relação com a educação e a escola. Pois uma boa parte da juventude local estuda fora do 'espaço rural', por não haver escolarização em níveis mais elevados (Ensino Médio e Superior). E também o fato de que a própria comunidade se abre hoje a novas formas de produzir a agricultura, de lidar com a terra, e de se apropriar de outros saberes, outros conhecimentos, outras informações, quase sempre provenientes da cidade.

Outro aspecto interessante ressaltado na obra de Wanderley (2011) e que está presente na realidade pesquisada é o "conhecimento sobre os sujeitos rurais em toda a sua diversidade e complexidade", ou seja, não é possível organizar uma frente de luta em favor de um 'mundo rural' - incluem-se aqui os intelectuais, os movimentos sociais e os técnicos da educação - sem interagir com uma dada realidade rural e seus sujeitos. Sem se perceber quem eles são, como vivem, o que sabem, o que enfrentam para a sua sobrevivência, e o que desejam em suas vidas no território rural. (WANDERLEY, 2011:106).

Muitas são as questões que a realidade nos incita, mas há uma, em especial, que mais nos inquieta e que justificaria nossa escolha temática e, principalmente, a escolha pela comunidade Nossa Senhora do Perpétuo Socorro como locus de nossa interação de investigação deste artigo. Ela é a condição de vida do homem e da mulher rural e os seus conhecimentos patrimoniais, além do questionamento sobre a dimensão pedagógica e política da escola quilombola em seu projeto de contribuir para o fortalecimento de saberes e de uma identidade ao mesmo tempo culturalmente étnica e socialmente rural. Estas e outras questões serão abordadas na próxima seção.

\section{O reconhecimento das culturas locais na educação escolar}

Quando fazíamos os percursos ao 'campo', uma das questões mais inquietantes foi verbalizada por uma moradora da 
comunidade e trabalhadora rural que dizia: "hoje não temos nada pra comer". Essa senhora era uma mulher com dez filhos, como ela dizia, "todos escadinha". Descrevendo sua vida naquele lugar, ela foi expondo o teor de suas relações com a natureza, o modo como educa os seus filhos, a sua relação com a vizinhança e assim por diante. E ela lamentava que a vida ali não era fácil. Sua narrativa colocava-nos um problema: de um lado, a condição de vida do trabalhador rural e seus conhecimentos e de outro, a função da escola quilombola naquele contexto.

Em outro patamar, o que caracteriza a comunidade é, como vimos, o cultivo da agricultura familiar e os modos de vida ancorados em uma peculiar "ruralidade" social. Assim, o movimento da cultura local é observado também nos sons da natureza, no barulho das marés, e são sons tão escassos ou não presentes em nossa 'urbanidade'. E é vivido também na ausência de água potável em uma comunidade com abundância deste líquido; na conversa dos moradores familiarizados com a terra, com as fases da lua, com a quentura do sol, com a extensão e com a frequência da chuva, com o encantado rio; com a crença nos mitos da Matinta Perera, do Boto, da Cobra Grande, todos eles ricos, naturais e fantásticos elementos demonstrativos da terra amazônica. Essas representações configuram a própria vida da comunidade, e são elementos culturais reais que participam da vida cotidiana e que se articulam com o tempo-espaço da educação escolar. Logo, não podem estar ausentes do currículo escolar. E, principalmente, a questão da fome, citada anteriormente, como um elemento de problematização no contraste entre a riqueza cultural existente e as ausências com que lidam as pessoas do lugar.

O cultural local também se manifesta na presença e na pauta reivindicatória dos movimentos sociais e das demais organizações existentes, que, pela 'condição do viver no lugar', estabelecem as suas lutas a busca em nome de melhorias dos processos produtivos dos agricultores, pela terra, pelo acesso a políticas sociais, entre outras questões. Neste aspecto são vários os movimentos sociais em Abaetetuba, que atuam em favor de melhores condições de vida para a população ribeirinha e quilombola. Entre as organizações 
|158|

O rural quilombola...

sociais, destacam-se: a Associação dos Moradores das Ilhas de Abaetetuba (AMIA), o Movimento dos Ribeirinhos e Ribeirinhas das Ilhas e Várzeas de Abaetetuba (MORIVA), o Sindicato dos Trabalhadores e Trabalhadoras Rurais (STTR) e a Associação dos Remanescentes de Quilombos das Ilhas de Abaetetuba (ARQUIA).

Ao falar da região amazônica paraense, especificamente da construção da identidade ribeirinha e quilombola, não há como deixar de mencionar os saberes das culturas seculares dos povos das florestas - os indígenas e os negros. Em suas identidades trazem como herança modos de vida indígena e da origem afro, no conjunto de suas relações com o ambiente natural, e em suas formas de resistência à hegemonia da cultura branca, entre tantos outros aspectos.

É nesta geografia que a pesquisa se desenvolveu, envolvendo a presença e a atuação da escola pública municipal Santo André, no rio baixo Itacuruçá, e da Escola São João Bosco, no rio Arapapuzinho. Aliás, em se tratando deste pedaço da Amazônia, não é exagero afirmarmos que todo o movimento populacional e econômico é realizado pelos rios, tão fortes na vida da comunidade, tanto que é pelo nome deles que a escola e a comunidade são identificadas. Ou seja, os nomes pelos quais a comunidade se orienta, identifica-se, e se conhece e se reconhece é pelo nome dos rios.

A respeito do campo educacional existente e do atendimento veiculado às populações ribeirinhas e quilombolas, presenciamos algumas situações comuns no lugar: o atendimento funciona, em sua maioria, com o Ensino Fundamental e a Educação Infantil e organiza-se em classes multisseriadas; a maioria dos professores e funcionários faz a travessia da cidade até os lugarejos diariamente; uma parte significativa dos alunos é transportada em embarcações; o acesso à internet e à telefonia é precário. Alguns professores estão cursando graduação pelo Plano Nacional de Formação de Professores da Educação Básica (PARFOR). Em meio a estes contrastes, observamos o esforço de um número significativo de profissionais que atua para que as ações educativas sejam de aprendizagem para todos. 
$\mathrm{Na}$ redondeza, as escolas são ditas como 'escolas quilombolas' e buscam, ainda que de forma incipiente, construir ações educativas assentadas nas necessidades das populações na tentativa de fazer valer uma escolarização de qualidade social.

Nessa perspectiva, o espaço educacional tem assumido até onde pode a tarefa de construir processos emancipatórios, na interface com vários campos da vida humana, como a organização da produção local, como os espaços de convivência, como a organização política e social dos movimentos sociais, trazendo para esse locus uma relativa mediação por meio de manifestações culturais do lugar, pois o 'rural' ribeirinho e quilombola possui uma diversidade cultural. Ele é um lugar territorializado por sujeitos sociais, políticos, econômicos e culturais diferentes.

A educação escolar nesse lugar possui uma importância comunitária incomensurável. De fato, os espaços escolares são respeitados e prestigiados pela grande maioria dos moradores locais, principalmente dada a perspectiva de melhoria de vida que a certificação e o percurso formativo dos alunos podem lhes proporcionar. Por isso, vivenciar a interlocução entre conhecimento científico e saberes dos ribeirinhos e quilombolas pode ser uma boa inspiração para se retomar a questão sempre latente de que, "historicamente, a nossa sociedade e a escola que lhe é própria não desenvolviam - e não desenvolvem - mecanismos democráticos perante as diversidades social e cultural" (GUSMÃO, 1997:2).

Não é a propósito que a Escola Santo André traz o título de primeira escola quilombola no município de Abaetetuba, por ser oriunda das lutas dos movimentos sociais em nome da garantia da diversidade étnica dessas populações. E por isso ela carrega o valor de 'ser diferente'. No entanto, acreditamos que essa complexa e desafiante tarefa só terá impacto social se, à medida em que o ensinar-aprender dialogar com os problemas presentes, na prática da agricultura e em nome das famílias, de nas propriedades e de seu cotidiano do trabalho, aspirando contribuir na sedimentação do potencial 'rural' existente, ao potencializar os saberes e as experiências culturais dos estudantes com aprendizagens vitais, não legitimadas e ameaçadas num 'rural' vivo. Em síntese, 
$|160|$

O rural quilombola...

tudo depende delas aprenderem a se 'agriculturalizarem', se 'amazonizarem', se 'ribeirinizarem' e se 'campesinizarem', e também ao seu currículo escolar, para que dessa forma aprendam o gosto, o prazer e a luta de ser um ribeirinho e quilombola com direitos e vida digna.

No caso específico, significa acenar na direção de outra 'margem' a construção de políticas públicas voltadas a esses territórios, visando de fato um processo de desenvolvimento humano. Pois, "apesar da perda demográfica constatada, existe uma parcela significativa de brasileiros que vive nesses espaços rurais". E a 'travessia educativa' não se faz sem a interlocução com as lutas sociais, com os saberes dos agricultores, com o reconhecimento das culturas locais, oriundas da tradição ribeirinha e quilombola na educação escolar, na perspectiva da recriação das identidades, do empoderamento com o lugar, com sua gente e, dessa forma, assumindo uma concepção educativa mais ampla e situada historicamente (WANDERLEY, 2011:110).

\section{Considerações Finais}

Por meio da pesquisa realizada, percebemos que os modos culturais de significar a existência passam pela ruralidade presente na comunidade estudada. Assim sendo, frente à ação educativa está posta a "pertinência do rural como espaço específico, com suas relações econômicas, sociais, políticas e culturais" visando o útil à vida humana. Reconhecendo que o lugar de quilombolas e ribeirinhos é um espaço de partilha da vida, no qual a escola potencializa sua identidade social gerada na teia de relações ali estabelecidas (WANDERLEY, 2011:119; BRANDÃO, 1995). O compartilhamento da vida 'rural' está nas peculiaridades do cotidiano expressa por meio da relação que estabelecem com os tempos, com os espaços de aprendizagem, com as formas de linguagem, por meio dos repertórios orais em que demonstram um modo próprio de produzir sua territorialidade na história do lugar. Uma representação evidente, entre tantas, é o entusiasmo 
com que falam de um dos traços culturais dos quilombos ainda existente na comunidade. Vejamos o que diz Pérola, moradora da comunidade do rio Arapapuzinho:

\begin{abstract}
A Simbolada é um resgate cultural que faz parte da cultura quilombola. A cultura nossa mesmo, aqui da região. Ela acontecia quando tinha as festas nos casarões, que na época não era aparelhagem e eles próprios inventavam as mudinhas e os instrumentos. O Cambi é um tipo de uma dança. (2013).
\end{abstract}

Este traço cultural demonstra a capacidade de resistência e persistência em favor de um modo próprio de viver em sua diversidade com práticas sociais que, por si só, educam. Este modo próprio necessita de registro e, de alguma forma, significa dignificar o patrimônio mitológico, linguístico, arqueológico e sociológico, sem o qual a sua identidade de ribeirinho e quilombola corre o risco de se ver contestada e deslegitimada.

Dessa forma, perspectivar o 'rural' suscita pensá-lo de forma complexa na rede de relações aí embutidas como as formas de trabalho, como as ausências que convivem, como os diversos lugares, em tempos e espaços diversificados, onde esse território é "um mundo rural povoado, frequentemente portador de dinamismo econômico e social e onde campo e pequena cidade são complementares", assim como, para além da polaridade 'urbanorural', "o que está em questão são as relações que se estabelecem entre o mundo rural e o mundo urbano, que expressam o significado da ruralidade na sociedade contemporânea" (WANDERLEY, 2011:109).

Para a educação escolar, a condição étnica e a condição histórica, aqui no sentido do cultural, expressa na comunidade como parte das questões sociais, é um permanente devir diante das escolhas curriculares e sua organização. Isso obriga a escola a não se deter na precariedade, mas, sim, no potencial do lugar e das pessoas. 
$|162|$

O rural quilombola...

Finalmente, não é intenção se fechar num campo de ideias, ao contrário, parece-nos mais adequado dizer que o escrito é apenas o começo de uma reflexão que será mais aprofundada, pois

o debate teórico e metodológico das chamadas pesquisas educativas, relacionadas às diversas $\mathrm{e}$ diferentes formas de vida que, neste final de século, estão ainda a desafiar o conhecimento. Em jogo, as singularidades, as particularidades das sociedades humanas, de seus diferentes grupos em face da universalidade do social humano e sua complexidade através dos tempos e, em particular, num mundo que se globaliza (GUSMÃO, 1997:2).

Como a natureza da vida natural e social é a constante transformação, as comunidades ribeirinhas e quilombolas estão sujeitas às modificações ocorridas nas estruturas econômicas, socioculturais, educacionais, modificações lentas quando se trata de identidade como marca de um povo, de uma comunidade, de resistência no sentido de não mudar substancialmente suas ruralidades. O contexto rural se altera, pois ele não é uma moldura nem algo estático. Ao contrário, é admiravelmente exótico porque é singular no plural, o que exige que a ação educativa esteja sempre em permanente reflexão para tentar dizer o que é o rural quilombola e ribeirinho.

\section{Referências Bibliográficas}

ALMEIDA, M. W. B. de. O Estatuto da Terra e as Reservas Extrativistas. Reforma Agrária vol. 25, no 1, janeiro - abril. Revista da Associação Brasileira de Reforma Agrária,1995.

ALMEIDA, M. W. B. de. Quem são os povos da floresta? Cadernos SBPC 30. Povos da Floresta: Cobertura jornalística feita a partir de conferências e mesas-redondas apresentadas na 59 Reunião Anual da Sociedade Brasileira para o Progresso da Ciência (SBPC). 2007. 
ALMEIDA, M. W. B. de. Redescobrindo a família rural. Revista Brasileira de Ciências Sociais, São Paulo, v.1, n. 1, p. 66-83, jun. 1986.

ARQUIA/Associação dos Remanescentes de Quilombos das Ilhas de Abaetetuba. Estatuto Social. Abaetetuba, 26 de abril de 2012.

BRANDÃO. C. R. A partilha da vida. Série Cultura, Educação e Ambiente no Vale da Paraíba, 1. São Paulo: Geic/Cabral editora, 1995.

BRANDÃO. C. R. Educação como cultura. Campinas: SP: Mercado das Letras, 2002.

CPT/MORIVA. Nova Cartografia social da Amazônia: ribeirinhos e ribeirinhas de Abaetetuba e sua diversidade cultural. UEA: edições, 2009.

DIEGUES. C. Ilhas e Mares: simbolismo e imaginário. São Paulo: Hucitec, 1998.

FASE Amazônia. A Regularização fundiária na pauta dos movimentos sociais do Baixo Tocantins e o título de posse como estratégia dos movimentos sociais. Entrevista com Girolamo Treccani (Prof ${ }^{\circ}$ NAEA/UFPA). Série de Entrevistas sobre a Amazônia. Março de 2014.

FREIRE, P. F. A educação na cidade. 2ª ed. São Paulo: Cortez, 1995.

GUSMÃO, N. M. M. de. Antropologia e educação: Origens de um diálogo. Cadernos CEDES vol. 18, n. 43. Campinas, 1997.

GUSMÃO, N. M. M. de. Dossiê: Formação docente para a diversidade: dilemas, desafios e perspectivas no diálogo entre Antropologia e Educação. Pro-Posições v. 24, n. 2 (71) maio/ago, 2013. p. 17-25.

KAGEYAMA, A. A. Desenvolvimento rural: conceitos e aplicação ao caso brasileiro. Porto Alegre: UFRGS editora, 2008.

ROCHA, A. Os rios de Abaetetuba. 2012. Disponível em: $<$ HYPERLINK "http://ademirhelenorocha.blogspot.com.br/ 
$|164|$

O rural quilombola...

"http://ademirhelenorocha.blogspot.com.br>. Acesso em 13 ago. 2014.

UFPA. Projeto de pesquisa Travessias, identidades e saberes das águas - cartografias de saberes de populações ribeirinhas no Município de Abaetetuba-PA, 2012-2013. Prof ${ }^{a}$ s Eliana Pojo e Lina Glaúcia D. Elias (finalizado).

WANDERLEY, M. de N. B. Um saber necessário: os estudos rurais no Brasil. Campinas/São Paulo: Editora Unicamp, 2011. 